\title{
Journey from the Past to the Future in Raising the Ideal Physical Education Teacher: A Metaphor Study
}

\author{
Hande Baba Kaya ${ }^{1}$, Öznur Kara ${ }^{1} \&$ Pelin Ustaoğlu Hoşver ${ }^{1}$ \\ ${ }^{1}$ Faculty of Sports Sciences, Düzce University, Düzce, Turkey \\ Correspondence: Hande Baba Kaya, Faculty of Sports Sciences, Düzce University, Düzce. 81620 Yörük/Düzce, \\ Turkey. E-mail: handebabakaya@duzce.edu.tr
}

\author{
Received: July 5, $2021 \quad$ Accepted: August 10, $2021 \quad$ Online Published: August 30, 2021 \\ doi:10.5539/jel.v10n5p133 URL: https://doi.org/10.5539/jel.v10n5p133
}

\begin{abstract}
The aim of this research is to examine the ideal physical education profile from the perspective of physical education teacher educators, that is, academicians working in the physical education and sports teaching department of the faculties of sports sciences. Within the scope of this purpose, the views of the academicians about the pre-graduate education, the undergraduate education period and their own teaching were compared with their views on the ideal physical education teacher. In order to express the comparisons more clearly, metaphor was used. The academicians were asked to match the physical education teachers who influenced them the most from their past to the future, their own teaching and their views on the ideal physical education teacher, with the nature metaphor presented to them by the researchers. In the study, which was based on the qualitative research method, the "interview" approach and the "interview form method" were used as the data collection method. According to the stratified sampling method, the participants of the study; taking into account the academic titles of the participants; 3 professors, 3 associate professors, 3 assistant professor and 3 lecturers A total of 12 physical education teacher educators (academics) were determined. As a result of the research, it was observed that while the participants defined their pre-graduate teachers closer to the ideal teacher in terms of their physical characteristics, they defined their undergraduate physical education teachers and themselves as closer to the ideal physical education teacher in the main themes of personality traits, teacher leadership styles and teaching methods.
\end{abstract}

Keywords: ideal teacher, physical education, academician, metaphor

\section{Introduction}

Physical education is the process of deliberate change in an individual's behavior through physical activity. Physical education can also be expressed as the training of the individual with movement and physical way. (Tamer \& Pulur, 2001). Physical education is an activity that helps the development of the body's structure and function, provides the control and development of muscles and joints, teaches to use physical power economically and to act systematically. Physical education matures, develops and disciplines people physically, mentally and spiritually. It is a science that provides maximum benefit with minimum fatigue and includes many sports activities (Işler, 2012).

Physical education teachers are the most important factor in the processing of physical education lessons with the desired qualifications and maximum efficiency. Physical education teachers graduate from the faculties of sports sciences by taking theoretical and applied courses such as teaching formation knowledge, field and general culture knowledge in the four-year undergraduate program. When we examine the professional competencies expected from teachers who have completed their education; Each teacher knows how to plan the physical education lesson teaching process, to create environments in accordance with its purpose, to prepare materials for teaching and to benefit from resources, to help students gain basic and special movement skills, to realize their personal fitness levels, to have practices aimed at acquiring healthy life skills, to make the ceremonial programs effective. It includes the preparation and presentation of the school, cooperation with families, practices for the school to be a cultural and learning center, and supporting the physical education lesson teaching process, including the professional development practices of the teacher. In addition to these professional qualifications, the social qualities that a physical education teacher should have are the ability to communicate correctly, to be disciplined, to motivate, to exhibit good moral attitudes, good manners and positive 
behaviors, to be someone who can show his love to the students and to be interested in the needs of his students, to be willing to teach, caring can be expressed as being clean, well and tastefully dressed (Tamer \& Pulur, 2001).

All teachers are also leaders in their classrooms, and physical education teachers need to manage the classroom well in order to be successful in education and training activities (Seçgel, 2005). Each teacher has their own knowledge, skills, attitudes and behaviors and unique leadership styles in the education and training process. According to the leadership style, while some teachers teach with passive learning activities in an authoritative and oppressive manner, some teachers teach with active learning activities in a democratic and participatory manner. This situation is directly related to the leadership style of the teacher. While determining the leadership style of the teacher, it is affected by the students' perspective, values, attitudes, knowledge and experiences in the learning and teaching process (Güllü \& Arslan, 2009). The teacher's leadership style is a reflection of his personal characteristics. The teacher is commanding, affirming, tough, encouraging, soft, careful, playful, likes to let go, etc. features; The subject taught, the level of the class, the school's policy and the student's abilities determine his leadership style. The teacher can be an authoritarian, democratic or impassive leader. The teacher's leadership styles affect the general atmosphere of the classroom and the behavior of the student, as well as directly related to which behavior model he or she prefers (Tertemiz, 2006). The Autocratic Teacher believes that she has all the power as the leader of the class and wants her orders to be followed without question. It is possible to encounter strict disciplinary practices in classrooms where orders are not followed and are managed with an autocratic understanding. Teachers tend to resort to physical and psychological punishments and threats frequently in order to ensure that students reach the goals they set (Ağaoğlu, 2007). Autocratic teachers essentially keep the audience out of the administration. In other words, the audience has no say in determining the goals, plans and policies. They only have an obligation to comply with their leader's wishes. All of the management authority related to the group belongs to the leader (Demirbolat, 2006). In the democratic teacher style, authority and dominance are replaced by student-teacher interaction. They make arrangements to meet the needs of the students and to ensure that the teaching achieves its goals at the same time (Erdoğan, 2001). Democratic teachers are trained to share the authority to manage with their audience. The leader tends to give importance to the thoughts of the group members in determining the goals, plans and policies, and in the division of labor (Demirbolat, 2006). In a democratic management style, the teacher does not hesitate to openly show his interest and love to his students. In such a classroom culture, more emphasis is placed on success stories. They focus on positive behaviors rather than negative ones, and in reaching the goal, praise and encouragement take the place of threat and pressure (Ağaoğlu, 2007). It can be said that for the teacher who adopts the style of Irrelevant (Free), he delegates all his authority to the student. Teachers with free leadership style are the leaders who need the least authority to manage. They show a behavior that leaves the audience to their own devices. They are in training to leave their authority to group members rather than claiming their authority (Demirbolat, 2006).

The physical education teacher, who is the manager of the teaching activities in the physical education lesson, is not only a person with a high level of physical skills or who knows his subject well; At the same time, he is the person who can transfer these to his students, that is, enable them to learn and gain them. While doing these, the physical education teacher uses various teaching methods. Methodless activities produce random results. If appropriate and good management is selected and implemented, it is possible to achieve the objectives in a shorter time (Büyükkaragöz \& Çivi, 1997). A good physical education teaching method; It is a method that is suitable for the characteristics of the teaching activity with students and enables all students to participate and act at the highest level (Tamer \& Pulur, 2001).

Many methods can be mentioned about how to teach and learn sportive skills. The differences in the methods are due to the differences in the ways to be tried (Demirhan, 2006). In order for teachers to be selective about the method, they need to know and be able to use different methods (Demirel, 2004). The choice of the method to be used in teaching varies according to the purpose, scope and quality of the teaching. Besides; Factors such as the quality of the subject to be taught, educational goals, areas of behavior (cognitive, affective, kinetic), the teacher's tendency towards the method, the characteristics of the physical space, the quality of the tools and materials, the number of students, the teaching time and the cost-benefit situation affect the method selection. (MacNaughton \& Williams, 1998). Teaching methods used in physical education lessons; Narrative method: This method is ideal for presenting information of a generally cognitive nature, such as physical education facts (rules, history, ethics, etc.) and concepts (physiological effects of exercise, physical laws etc.). In this method, the teacher is the speaker and the student is the listener. Verbal explanation method: The purpose of this method is to explain the activity and analyze a concept or skill during the lesson. The teacher is the explainer and the student is the listener. It is a teacher-centered method. Demonstration method: The purpose of this method is to 
present the information visually by performing psychomotor activities.

In this method, auditory stimulation can be used together with movement. The role of the teacher in the method is planning, performing and interpreting the show. The student is in the role of receiver and listener (Tamer \& Pulur, 2001). Practice method: It is a learning activity in which students can improve themselves by applying and practicing the knowledge they have learned on their own. In this method, some decisions are transferred to the student. students establish new relationships among themselves and with their teachers during their studies. Students create new situations from the situations presented to them. While some of the students are responsible for the implementation of the movements, some of them are practitioners (Mosston \& Asworth, 2001). Assignment (Homework) method: (Individual Approach) The purpose of this method is to provide learning opportunities for students to learn skills, explore concepts or solve problems. In this method, the teacher plans the task and the student implements the given task. Paired working method: It aims to provide students with learning in cognitive, sensory and psychomotor areas. In this method, students work in pairs. Each spouse undertakes a task in the studies. While one of the spouses makes the desired action and makes the decisions about the movement, the other gives information about the performance of the spouse according to the criteria given by the teacher by following the action. Directed discovery method: It is aimed for students to discover appropriate solutions by themselves by giving them the opportunity to produce solutions to the problem presented to them. The role of the teacher in this method, sorting and planning problems; The student's role is to find and discover solutions. It is a student-centered teaching method. Problem solving method: This method is to enable students to find solutions on their own and freely to the problems presented through various learning experiences. Independent study method: It is a student-centered method, which is designed to develop students' interests and abilities and to gain the habit of independent study that provides learning by doing and requires a separate activity program for each student. Question-Answer method: The basis of this method is to find out the information to be taught by asking questions to the student himself. It is based on the students' verbal answers to the questions asked by the teacher. Assessment method: In this method, it is aimed to provide students with the opportunity to evaluate themselves through in-class and extra-curricular experiences. Media-assisted teaching method: It is tried to contribute to the learning process by offering different tools. This method is related to visual and auditory sense organs. In this method, the teacher is environment organizer and the student assumes the role of listener and observer (Tamer \& Pulur, 2001).

\section{Method}

\subsection{Research Model}

In this study, using the metaphor of "nature", physical education teacher educators (academics working in the physical education teaching department) encountered physical education teachers who left a mark on them in their high school education, in their university education, themselves as a physical education teacher and the physical education teachers who they trained that qualitative data collection technique was used in order to evaluate the views of teachers on physical and personal characteristics, teacher leadership style and teaching methods within the framework of the idea of how an ideal physical education teacher should be.

In the first stage of the research, qualitative research design was used, which primarily focuses on researching and understanding social phenomena in their environment. Qualitative research design is a method that adopts the approach of interpreting the multi-dimensional research problem in focusing on a certain point and gives priority to researching and understanding social phenomena in their environment (Kuş, 2003).

The fundamental basis of the research method of this research is the "phenomenology" paradigm, which is one of the disciplines that supports qualitative research and is the basis of theoretical foundations. The phenomenological approach, which accepts the source of knowledge as human, examines the events, situations, experiences, etc. faced by physical education teacher educators. Qualitative research was chosen and interview method was applied to reveal the concepts. For the study, the permission of the ethics committee of Duzce University, 02.04.2021, E-78187535-640-29633 was obtained.

\subsection{Participants of the Study}

This research is a qualitative research was carried out by using strata sampling method. Stratified sampling method is used in a universe consisting of subunits or strata groups and with certain boundaries (Yıldırım \& Şimşek, 2018). The universe of the research consists of academicians working in the physical education and sports teaching departments of universities. According to the stratified sampling method, the participants of the study; taking into account the academic titles of the participants; 3 professors, 3 associate professors, 3 assistant professor and 3 lecturers a total of 12 physical education teacher educators (academics) were included in the study. 


\subsection{Participants Profiles}

In the study, personal information of 12 physical education educators is given in Table 1.

Table 1. Personal Information of Participants

\begin{tabular}{lllll}
\hline Participants & Gender & Age & Professional seniority year & Title \\
\hline P1 & M & 55 & 24 & Professors \\
P2 & M & 52 & 24 & Professors \\
P3 & W & 52 & 30 & Professors \\
P4 & W & 58 & 30 & Associate professor \\
P5 & W & 37 & 11 & Associate professor \\
P6 & W & 40 & 15 & Associate professor \\
P7 & M & 39 & 18 & Assistant Professor \\
P8 & M & 38 & 9 & Assistant Professor \\
P9 & M & 45 & 20 & Assistant Professor \\
P10 & W & 34 & 10 & Lecturer \\
P11 & M & 33 & 4 & Lecturer \\
P12 & M & 29 & 2 & Lecturer \\
\hline
\end{tabular}

\subsection{Data Collection and Preparation of Interview Form}

\subsubsection{Preparation of the Interview Form}

In the research, "interview" approach and "interview form method" were used as data collection method. In order to develop the interview form, questions were formed in the light of the data obtained by scanning the relevant literature and seeking expert opinions. "Who is a good teacher?", "How to train a good teacher?", "What are the criteria for evaluating a teacher?", "He is a very good teacher or not a good teacher", etc. are constantly asked or similar expressions are used, what is the criterion of goodness? Why is this teacher not good? What are the student's criteria? Although the answers to these questions vary according to philosophical trends, goals, teacher training style and culture, they are shaped in three common dimensions (MEB, 1997). In the formation of these questions, these three common dimensions formed the basic framework and are given in Figure 1 as headings.

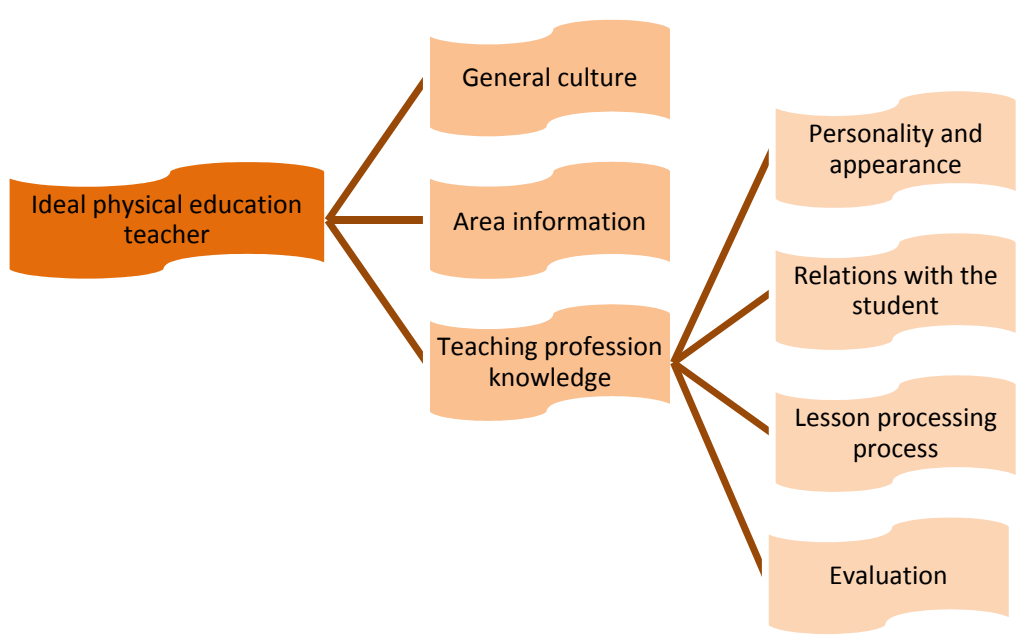

Figure 1. The literature forming the interview questions; main topics

Meeting with a qualitative research expert, these questions were discussed and the form was finalized. A pilot interview was conducted with 1 participant so that the questions could be asked in the appropriate order. After the necessary arrangements were made at the end of the interview, the participants who formed the group within the scope of the research were determined and the interviews were started by taking appointments. In addition, different nature forms (photographs) were selected. While making the selection, the general culture, content 
knowledge, personality and appearance, teaching methods and teacher leadership style of a physical education teacher and the nature forms that are thought to reflect the feeling or impression created by the participants as a whole were selected. At the end of the talks; The participants were asked to se the existing and desired nature nature shape from among 4 different shapes.

\subsubsection{Interview}

During the interview process, volunteerism was based on the structure of qualitative research. A pilot interview was conducted with 1 participant for the application reliability of the questions about the metaphor and the interview form. The participant selected for the pilot interview was considerebe an expert in qualitative studies, studies, her experience and opinions were taken for the order and clarity and necessary arrangements were arrangements were made. Participants who were interviewed were not includedata. Interviews were conducted were conducted face-to-face with the participants at venues chosen accordirxith written permission from the permission from the participants. Voice recordings of the participants were mad There was no restriction on the restriction on the answers given by the participants to the questionsThe answers included in the research were not research were not limited to the questions that were created before, and anle was followed. It has been tried followed. It has been tried to collect as detailed and in-depth data as possible ahterviews recorded on the voice recorded on the voice recorder were deciphered by the researcher immediately ad turned into prose. Coding was prose. Coding was done by the researcher and a qualitative research expert.

\subsubsection{Metaphor}

In this study, using the metaphor of "nature", physical education teacher educators (academics working in the physical education teaching department) encountered physical education teachs who left a mark on them in their their high school education, in their university education, themselves as a phlucation teacher and the physical physical education teachers who they trained physical education teachers werened data about personality and and appearance, teacher leadership style, teaching methods, field knowledge anderal culture

The Meanings of the Metaphors Used in the Research

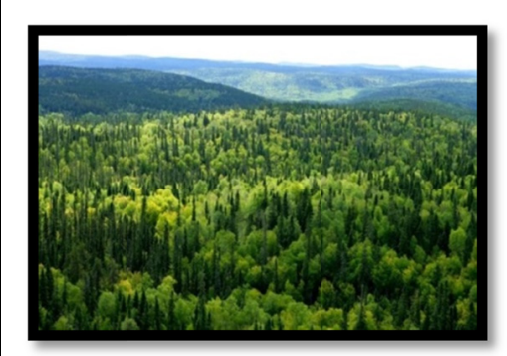

FOREST

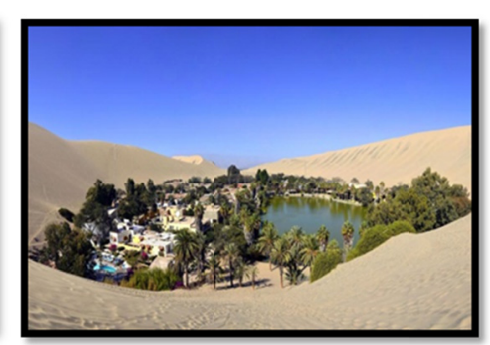

OASIS

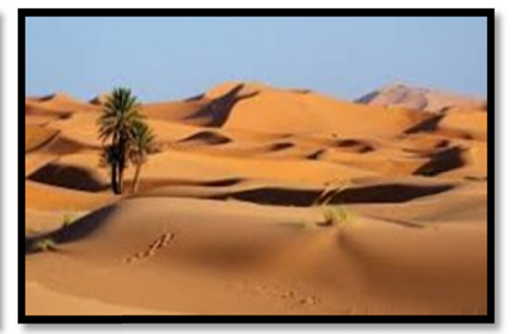

DESERT

Forest: It is a landform that exists with the living things it contains and sets them free. It provides equal opportunity for life to all living things, is home to many animals, contains many plants, and is a great source of oxygen with its lush trees. It gives life with its inspiring beauty.

Oasis: It is a landform that allows living things to live within the limits determined by it due to the negative conditions around it, but leaves them free within those limits. It is a region ted in deserts and isolated from from desert conditions, generally containing water and plants as a source of liough it stays under the adverse adverse conditions of the desert climate from time to time, it manages to wn natural beauty. Although it Although it provides an opportunity for the life of living things, it is not sinds of living things, that is, it things, that is, it hosts a limited number of living things.

Desert: It has an atmosphere that dominates because of its climatic difficulties. It has a very difficult climate for survival and for living things to live. They are unproductive lands where plants do not grow. It is very difficult to adapt due to the temperature difference between night and day. Idstorms from time to time can can end people's lives. It is visually monotonous and disturbing.

\subsubsection{Interview Stages}

Stage 1: The participants were asked to think of various characteristics of physal education teachers (in terms of of physical, personality, teacher leadership style and teaching methods) as a na and were asked to describe their their perceptions of nature. 
Stage 2: Interview questions were asked in detail.

Stage 3: In order to show the participants in the research, the nature shape and photograph with four different distinctive features were chosen by the researcher and the expert (scientific experienced person in qualitative research and metaphor work). The selected nature photographs, illustrated in six different A4 sizes, were shown to the participants, and they were asked to choose what they wanted from the existing nature.

\subsection{Analysis of Data}

In the research, "descriptive analysis" method is used in order to analyze the data in an understandable way to reach some results by examining the cause-effect relationships and to interpret the findings, to bring together similar data within the framework of certain concepts and themes, and to analyze the findings that may be hidden in the data. "Content analysis" method was used to reveal the facts.

Coding the Data: The data obtained through interviews using a voice recorder were converted into prose on the computer. Then, the expressions that were expressed in the data were coded as short sentences. Encodings are written right next to the data written in prose by marking the lines. The overlapping themes of these codings were grouped by the researcher. In the analysis of qualitative data, the interviewed participants were P1, P2, P3 ... coded as.

\section{Findings and Comments}

The data obtained as a result of the interviews were presented as 5 main themes. These; physical education teacher trainers (academics working in the physical education teaching department);

1) Main Theme: Comments and metaphorical analogy about your physical education teacher who influenced you the most in your pre-university education life.

a) Your teacher's physical characteristics

b) Personal characteristics of your teacher

c) Your teacher's teacher leadership style

d) Your teacher's teaching methods

2) Main Theme: Comments and metaphorical analogy about your teacher who influenced you most from your own department teachers who trained you as a teacher in your university education

a) Your teacher's physical characteristics

b) Personal characteristics of your teacher

c) Your teacher's teacher leadership style

d) Your teacher's teaching methods

3) Main Theme: As an academician who trains teachers at the university; comments and metaphorical analogy about your own teaching

a) Your physical characteristics

b) Personal characteristics of yourself

c) Your own teacher leadership style

d) Your own teaching methods

4) Main Theme: Comments on your ideal physical education teacher

5) Main Theme: Comments on the similarity of the students you have trained to the ideal teacher you describe 
Table 2. Opinions of the participants about the physical education teacher who influenced them the most before their undergraduate education

\begin{tabular}{|c|c|c|c|}
\hline THEME & SUB- THEME & CODING & $\mathrm{f}$ \\
\hline \multirow[t]{8}{*}{ Physical characteristics } & \multirow[t]{2}{*}{ Height } & Tall & 5 \\
\hline & & Short & 3 \\
\hline & \multirow[t]{2}{*}{ Gender } & Man & 10 \\
\hline & & Women & 2 \\
\hline & \multirow[t]{4}{*}{ Appearance } & Clean-Maintained & 10 \\
\hline & & Sportswear & 7 \\
\hline & & Athletic-Fit & 7 \\
\hline & & Matching clothing & 5 \\
\hline \multirow[t]{11}{*}{ Personality characteristics } & \multirow[t]{5}{*}{ Compatibility } & Fatherly & 7 \\
\hline & & Kind but firm & 5 \\
\hline & & Friendly & 3 \\
\hline & & Softhearted & 2 \\
\hline & & Calm & 2 \\
\hline & \multirow[t]{3}{*}{ Extraversion } & İdealist & 3 \\
\hline & & Unselfish & 3 \\
\hline & & Sincere & 2 \\
\hline & \multirow{3}{*}{ Responsibility } & Fair-Reliable & 7 \\
\hline & & Disciplined & 4 \\
\hline & & Strong & 2 \\
\hline \multirow[t]{7}{*}{ Teacher leadership style } & \multirow[t]{3}{*}{ Democratic/tolerant teacher } & Fair-Reliable & 5 \\
\hline & & Students care about & 5 \\
\hline & & Role Model & 2 \\
\hline & \multirow[t]{2}{*}{ Theocratic/authoritarian teacher } & Disciplined & 7 \\
\hline & & Oppressive & 5 \\
\hline & \multirow[t]{2}{*}{ Free/indifferent Teacher } & Non-teaching & 3 \\
\hline & & İndifferent to student & 2 \\
\hline \multirow[t]{9}{*}{ Teaching methods } & \multirow[t]{3}{*}{ General teaching methods } & Demonstration method & 11 \\
\hline & & Narration method & 8 \\
\hline & & Cooperative Learning & 2 \\
\hline & \multirow[t]{6}{*}{ Special teaching methods } & Command method & 7 \\
\hline & & Co-working & 6 \\
\hline & & Practice method & 3 \\
\hline & & Participation Method & 2 \\
\hline & & Problem solving & 2 \\
\hline & & Directed Invention & 2 \\
\hline
\end{tabular}

In Table 2, when the opinions of the participants about the physical education teacher who influenced them the most before their undergraduate education were examined; It is seen that there are four main themes (physical characteristics, personality traits, teacher leadership styles and teaching methods). Height, gender and appearance appearance sub-themes were created under the main theme of physical characteristics. The highest frequency in the height sub-theme was tall $(\mathrm{n}=5)$, the highest frequency in the gender sub-theme was male $(\mathrm{n}=10)$, the highest frequency in the appearance sub-theme was clean-groomed $(\mathrm{n}=10)$, athletic-fit $(\mathrm{n}=7)$ and sportswear $(\mathrm{n}=7)$ coding. coding. Three sub-themes were formed under the main theme of personality traits: compatibility, extroversion, and and responsibility. Under the compatibility sub-theme, those with the highest frequency were fatherly $(\mathrm{n}=7)$ and sweet-hard $(\mathrm{n}=5)$; Those who received the highest frequency under the sub-theme of extraversion were idealistic $(n=3)$ and selfless $(n=3)$; It is seen that those with the highest frequency in the responsibility sub-theme are fair-reliable $(n=7)$ and disciplined $(n=4)$. It is seen that three sub-themes (democratic/tolerant, theocratic/authoritarian, free/indifferent) are formed under the main theme of teacher leadership styles. The coding coding with the highest frequency under the Democratic/Tolerant sub-theme was fair-reliable $(n=5)$ and caring for for the student $(\mathrm{n}=5)$, while the coding with the highest frequency under the theocratic/authoritarian sub-theme was disciplined $(\mathrm{n}=7)$ and oppressive $(\mathrm{n}=5)$, free/irrelevant sub-theme, it is seen that the coding that does not teach teach $(n=3)$ and is not interested in the student $(n=2)$. Under the main theme of teaching methods, it is seen that two two sub-themes are formed, namely general teaching methods and special teaching methods. Demonstration $(\mathrm{n}=11)$ $(\mathrm{n}=11)$ and expression method $(\mathrm{n}=8)$ of the codings with the highest frequency in the sub-theme of general teaching methods, the command method $(n=7)$ and co working $(n=6)$ of the codings with the highest frequency 
under the sub-theme of special education can be seen.

Sample expressions of the participants under the main theme of physical characteristics;

P9: Our teacher was male, tall, well-groomed, sporty dressed, usually wearing tracksuits, and always came to classes with a whistle. He is the teacher who left the most physical mark for me.

P11: He was a tall, athletic male teacher who was careful about his clothes and looked clean and well-groomed.

P5: He was a male teacher, well-groomed, tall, athletic, conspicuous, and carefully dressed, he usually came to class in sports sweatpants.

Sample expressions of the participants under the main theme of personal characteristics;

P1: He was not an oppressive teacher, he was generally a fatherly, loving, helpful personality.

P12: He was an honest, selfless, empathetic, disciplined, fatherly, well-intentioned teacher.

P7: He was an idealistic person, a self-sacrificing, determined, disciplined, sweet and tough teacher who gave direction to his students.

P3: My physical education teacher had a sweet, tough, disciplined personality.

Sample expressions of the participants under the main theme of teacher leadership style;

P8: Our teacher had a high level of field knowledge, he would support the athletes in his own branch, but he never reflected this to the lessons and treated all students fairly and equally. He was very disciplined, he wanted to see everyone ready and in sweatpants before the lesson started, and he made it mandatory.

P7: Usually he would let it go in the lessons, he would play games, but he did not allow uncontrolled behavior, he was disciplined.

P10: He considered the individual differences of the students, taught his lessons accordingly, and treated students fairly and equally in the classroom.

P6: Although the class sizes were crowded, he motivated each student to attend the lesson and tried to make each student learn the movement.

Sample expressions of the participants under the main theme of teaching methods;

P11: He used the participation method while doing the layout exercises, he was using the practice method, which was the first time I had thrown a shot put in that lesson, he would show it first and have it done, and he would also use the paired working method.

P2: He would show the practice lessons himself and ask us to do it afterwards. He used the practice method.

P3: He mainly used the command method and mostly used the narration method. Apart from this, he also used the show-and-make method.

Table 3. Metaphors of the participants about their views about the physical education teacher who influenced them the most before their undergraduate education

\begin{tabular}{lll}
\hline Theme & Metaphor & $\mathrm{f}$ \\
\hline Physical characteristics & Forest & 8 \\
& Oasis & 3 \\
& Desert & 1 \\
Personality characteristics & Forest & 6 \\
& Oasis & 5 \\
\multirow{5}{*}{ Teacher leadership style } & Desert & 1 \\
& Forest & 4 \\
Teaching methods & Oasis & 7 \\
& Desert & 1 \\
& Forest & 2 \\
& Oasis & 7 \\
\hline
\end{tabular}

In Table 3, the frequencies of the metaphor images that the participants preferred about the four main themes among the metaphors (forest, oasis, desert) presented about the physical education teacher that most influenced them before their undergraduate education were examined. The most preferred metaphor was forest $(n=8)$ in the 
main theme of physical characteristics, forest $(n=6)$ in the main theme of personality traits, oasis in the main theme theme of teacher leadership styles $(n=7)$, and oasis in the main theme of teaching methods $(n=7)$ is seen.

Table 4. Opinions of the participants about the physical education teacher who influenced them the most during their undergraduate education

\begin{tabular}{|c|c|c|c|}
\hline THEME & SUB- THEME & CODING & $\mathrm{f}$ \\
\hline \multirow[t]{11}{*}{ Physical characteristics } & \multirow[t]{3}{*}{ Height } & Medium height & 4 \\
\hline & & Tall & 3 \\
\hline & & Short & 2 \\
\hline & \multirow[t]{2}{*}{ Gender } & Man & 8 \\
\hline & & Women & 4 \\
\hline & \multirow[t]{6}{*}{ Appearance } & Clean-Maintained & 8 \\
\hline & & Sportswear & 7 \\
\hline & & Weak & 5 \\
\hline & & Athletic-fit & 4 \\
\hline & & Classic clothing & 3 \\
\hline & & Overweight & 2 \\
\hline \multirow[t]{9}{*}{ Personality characteristics } & \multirow[t]{5}{*}{ Compatibility } & Open to contact & 4 \\
\hline & & Fatherly & 3 \\
\hline & & Honest & 2 \\
\hline & & Calm & 2 \\
\hline & & Sweet-hard & 2 \\
\hline & \multirow[t]{2}{*}{ Neurotic } & Contact closed & 2 \\
\hline & & Hard & 2 \\
\hline & \multirow[t]{2}{*}{ Responsibility } & Disciplined & 6 \\
\hline & & Reliable & 4 \\
\hline \multirow[t]{11}{*}{ Teacher leadership style } & \multirow[t]{7}{*}{ Democratic/tolerant teacher } & Fair & 6 \\
\hline & & High knowledge of the field & 5 \\
\hline & & Open to contact & 4 \\
\hline & & Student caring & 2 \\
\hline & & Role Model & 2 \\
\hline & & Motivating & 2 \\
\hline & & Devoted & 2 \\
\hline & \multirow[t]{4}{*}{ Teokratik-Otoriter öğretmen } & Disciplined & 4 \\
\hline & & Punctual & 4 \\
\hline & & Oppressive & 2 \\
\hline & & Low motivation & 3 \\
\hline \multirow[t]{10}{*}{ Teaching methods } & \multirow[t]{4}{*}{ General teaching methods } & Narration method & 9 \\
\hline & & Demonstration method & 7 \\
\hline & & Question-answer method & 6 \\
\hline & & Discussion method & 2 \\
\hline & \multirow[t]{6}{*}{ Special teaching methods } & Command method & 4 \\
\hline & & Practice method & 4 \\
\hline & & Co-working & 3 \\
\hline & & Self assessment & 2 \\
\hline & & Participation Method & 2 \\
\hline & & Directed Invention & 2 \\
\hline
\end{tabular}

In Table 4, when the opinions of the participants about the physical education teacher who influenced them the most during the undergraduate education period are examined; It is seen that there are four main themes (physical (physical characteristics, personality traits, teacher leadership styles and teaching methods). Height, gender and appearance sub-themes were created under the main theme of physical characteristics. The highest frequency in the height sub-theme was medium height $(n=4)$, the highest frequency in the gender sub-theme was male $(n=8)$, the the highest frequency in the appearance sub-theme was clean-groomed $(n=8)$ and sporty clothing $(n=7)$ It is seen that they are gathered under the coding. Three sub-themes were formed under the main theme of personality traits: traits: compatibility, neuroticism and responsibility. Those with the highest frequency under the sub-theme of compatibility are open to communication $(n=4)$ and paternalistic-motherly $(n=3)$; The codings formed under the neurotic sub-theme were noncommunicative $(n=2)$ and harsh $(n=2)$; It is seen that those with the highest frequency 
frequency in the responsibility sub-theme are disciplined $(n=6)$ and fair-reliable $(n=4)$. It is seen that two sub-themes (democratic/tolerant, theocratic/authoritarian) are formed under the main theme of teacher leadership styles. The coding with the highest frequency under the Democratic/Tolerant sub-theme was just-egalitarian $(\mathrm{n}=6)$ $(n=6)$ and with high content knowledge $(n=5)$, while the coding with the highest frequency under the theocratic/authoritarian sub-theme was punctual $(n=4)$ and disciplined $(n=4)$. Under the main theme of teaching methods, it is seen that two sub-themes are formed, namely general teaching methods and special teaching methods. In the sub-theme of general teaching methods, the method of expression of the codings with the highest frequency $(n=9)$, demonstration $(n=7)$ and question-answer method $(n=6)$; It is seen that the codings with the highest frequency under the sub-theme of special education are command method $(n=4)$, practice method $(n=4)$ and paired study $(\mathrm{n}=3)$.

Sample expressions of the participants under the main theme of physical characteristics;

P9: He was a male teacher. He was of medium height, sporty dressed, always wearing sweatpants. His appearance was always well-groomed.

P1: He was of medium height, but a teacher's height has a perceptual effect on being a good teacher, for example, Tall teachers are seen as better teachers, but ingenuity is in teaching skill, not height.

P3: She was a female teacher of ours, she was a national athlete, she was not tall, but she had an athletic build, dressed sportily and was a well-groomed teacher.

Sample expressions of the participants under the main theme of personal characteristics;

P10: He was sweet-hard, embracing all students, fatherly, cute, but he had a discipline that provided discipline when he did not fulfill his expectations in the lesson.

P6: He was a moderate and calm teacher, and the students respected him.

P8: His communication was very good, he understood the language of the student very well.

Sample expressions of the participants under the main theme of teacher leadership styles;

P2: He was very meticulous in the lessons, he showed the movements himself, he treated all students in an objective way.

P9: He treated everyone equally, he was a teacher that I took as a role model, he was a just, fatherly and self-sacrificing person.

P2: Communication with his students was very good, we could easily share our every problem with him, he did not discriminate, he valued all his students, he was a just teacher. Class control was good, he tried to involve the whole class.

Sample expressions of the participants under the main theme of teaching methods;

P8: Our teacher had very good content knowledge, he used all teaching methods, there was no teaching method that he did not use in the lesson.

P2: He usually used the command method, the lecture method and the paired working method in the lessons. He used to show us a move or the skill he wanted us to gain, and then he would make him do it.

P10: He used the show-and-make method, he used to show himself before, then he used the practice method. In addition to these, the command method is already used extensively in basic physical education classes. He used the lecture method in the theoretical knowledge of the courses. 
Table 5. Metaphors of the participants about their views about the physical education teacher who influenced them the most during their undergraduate education

\begin{tabular}{lll}
\hline Theme & Metaphor & f \\
\hline Physical characteristics & Forest & 5 \\
& Oasis & 7 \\
Personality characteristics & Desert & - \\
& Forest & 9 \\
& Oasis & 3 \\
Teacher leadership style & Desert & - \\
& Forest & 9 \\
Teaching methods & Oasis & 1 \\
& Desert & 2 \\
& Forest & 7 \\
& Oasis & 3 \\
\hline
\end{tabular}

In Table 5, the frequencies of the metaphor images that the participants preferred about the four main themes among the metaphors (forest, oasis, desert) presented about the physical education teacher that most influenced them during their undergraduate education were examined. The most preferred metaphor in the main theme of physical characteristics is forest $(n=5)$, the main theme of personality traits is forest $(n=9)$, the main theme of teacher leadership styles is forest $(n=9)$, and the main theme of teaching methods is forest $(n=7)$ is seen.

Table 6. Opinions of the participants themselves about physical education and sports teaching

\begin{tabular}{|c|c|c|c|}
\hline THEME & SUB- THEME & CODING & $\mathrm{f}$ \\
\hline \multirow[t]{9}{*}{ Physical characteristics } & \multirow[t]{3}{*}{ Height } & Talll & 5 \\
\hline & & Short & 5 \\
\hline & & Medium height & 2 \\
\hline & \multirow[t]{6}{*}{ Appearance } & Clean-Maintained & 11 \\
\hline & & Athletic-fit & 7 \\
\hline & & Compatible clothing style & 5 \\
\hline & & Sportswear & 3 \\
\hline & & Weak & 3 \\
\hline & & Overweight & 2 \\
\hline \multirow[t]{15}{*}{ Personality characteristics } & \multirow[t]{8}{*}{ Compatibility } & Soft hearted & 4 \\
\hline & & Sharer & 4 \\
\hline & & Polite & 4 \\
\hline & & Sweet-hard & 4 \\
\hline & & Fatherly & 4 \\
\hline & & Calm & 3 \\
\hline & & Honest & 2 \\
\hline & & Emotional & 2 \\
\hline & \multirow[t]{5}{*}{ Extraversion } & Open to contact & 7 \\
\hline & & That can make empathy & 5 \\
\hline & & Sincere & 4 \\
\hline & & Open to criticism & 2 \\
\hline & & Innovator & 2 \\
\hline & \multirow[t]{2}{*}{ Neurotic } & Contact closed & 2 \\
\hline & & Hard & 2 \\
\hline \multirow[t]{11}{*}{ Teacher leadership style } & \multirow[t]{7}{*}{ Democratic/Tolerant Teacher } & Role-Model & 6 \\
\hline & & Just-Egalitarian & 5 \\
\hline & & student caring & 5 \\
\hline & & Understanding & 4 \\
\hline & & Idealist & 3 \\
\hline & & High leadership qualities & 3 \\
\hline & & Motivating & 2 \\
\hline & \multirow[t]{2}{*}{ Theocratic/Authoritarian Teacher } & Disciplined & 2 \\
\hline & & Punctual & 2 \\
\hline & \multirow[t]{2}{*}{ Freelance/Irrelevant teacher } & Insufficient classroom control & 2 \\
\hline & & Low motivation & 2 \\
\hline
\end{tabular}




\begin{tabular}{|c|c|c|c|}
\hline \multirow[t]{9}{*}{ Teaching methods } & General Teaching methods & Demonstration method & 8 \\
\hline & & Narration method & 7 \\
\hline & & Question-answer method & 6 \\
\hline & & Discussion method & 3 \\
\hline & & Video-assisted teaching & 2 \\
\hline & Special Teaching Methods & Co-working & 7 \\
\hline & & Command method & 3 \\
\hline & & Problem solving & 3 \\
\hline & & Directed Invention & 3 \\
\hline
\end{tabular}

When the views of the participants about physical education and sports teaching are examined in Table 6; It is seen that there are four main themes (physical characteristics, personality traits, teacher leadership styles and teaching methods). Height and appearance sub-themes were created under the main theme of physical characteristics. It is seen that the highest frequency in the height sub-theme is tall $(\mathrm{n}=5)$ and short stature $(\mathrm{n}=5)$, and in the appearance sub-theme, the highest frequency areas are gathered under the codes of clean-groomed $(n=11)$ and athletic-fit $(n=7)$. Under the main theme of personality traits, three sub-themes were created: agreeableness, extraversion and neuroticism. Those who received the highest frequency under the sub-theme of agreeableness $(n=4)$, sharing $(n=4)$, sweet-hard $(n=4)$, kind $(n=4)$ and fatherly-motherly $(n=4)$; extroversion sub-theme. The codings with the highest frequency under the theme were open to communication $(n=7)$ and empathetic $(n=5)$; It is seen that the codings formed under the neurotic sub-theme are non-communicative $(n=2)$ and harsh $(n=2)$. It is seen that three sub-themes (democratic/tolerant, theocratic/authoritarian and freelance/irrelevant teacher) are formed under the main theme of teacher leadership styles. Under the democratic/tolerant teacher leadership styles sub-theme, the coding with the highest frequency was found to be the role-model $(n=6)$ and just-egalitarian $(n=5)$ and caring for the student $(\mathrm{n}=5)$, the coding with the highest frequency under the theocratic/authoritarian sub-theme. It is seen that the codings formed under the sub-theme of punctual $(\mathrm{n}=2)$ and disciplined $(\mathrm{n}=2$, slowed down teacher type) are inadequate for classroom control $(\mathrm{n}=2)$ and low motivation $(\mathrm{n}=2)$. Under the main theme of teaching methods, it is seen that two sub-themes are formed, namely general teaching methods and special teaching methods. In the sub-theme of general teaching methods, coding with the highest frequency was demonstrated $(n=8)$, narrative method $(\mathrm{n}=7)$ and question-answer method $(\mathrm{n}=6)$; It is seen that the codings with the highest frequency under the special education sub-theme are paired work $(n=7)$, problem solving $(n=3)$, command method $(n=3)$ and directed discovery $(\mathrm{n}=3)$.

Sample expressions of the participants under the main theme of physical characteristics;

P7: I am tall and fit looking. I pay attention to my weight and take care of eating healthy, which affects my appearance. I think that physical education teachers should pay attention to themselves in this regard. I take care of my cleanliness and care. I dress sportily in applied classes.

P5: I'm medium height, but I can say that I'm the ideal height for a woman, I think I look thin and fit. I pay attention to my personal care, especially in sports environments, I always tell my students the importance of being well-groomed so that the bad smell caused by sweating does not prevent learning. Although I sometimes choose the classic style of clothing, I usually pay attention to dressing sporty in classes, especially with tracksuits. It is important for me to dress in harmony with the color match of the tracksuit and shoes.

P2: I'm middle height. I take care to be clean. The important thing is to attend classes in a way that will not lower the student's respect for you. I take care in this regard, I always do my hair and beard care.

P12: I take care to be clean and well-groomed, especially if I am going to wear tracksuits or dress classically, I pay attention to being clean, ironed and color harmony. In other words, I would like to capture the student visually.

Sample expressions of the participants under the main theme of personal characteristics;

P8: It has a sweet-hardy production. My students can share their ideas with me on any subject, I embrace my students and make them feel that I am always with them. I take care to act fairly and not to discriminate.

P10: The important thing for me is the students, I care about their development in every sense, so I act as a role model for them. I communicate with my students sincerely, in this sense, I have a sweet-hard structure.

P11: It's usually pretty quiet. I care about and support my students, they can easily communicate with me. I am an idealistic teacher, in this sense, I always become a role model for my students.

Sample expressions of the participants under the main theme of teacher leadership styles; 
P6: I can say that I am a democratic teacher, that is, open to communication, understanding, self-sacrificing and fair. I am a teacher who cares about his job and respects his work. I take care to improve myself and follow the innovations in the field.

P3: My classroom control is very good, even when I leave it empty in the classroom, I always follow who is doing what. I have my own strategies for involving the student in the lesson. I want each student to be active in the lesson. I take care of each and every one of them individually. I find myself at a very sufficient level in terms of field knowledge and I want to transfer my knowledge to the students. In this sense, I have a disciplined structure in the classroom, but I pay attention to be sincere with the students outside the classroom.

P11: The student sees me as close to him, I treat them as a friend, this connects us spiritually. And so it builds intimacy. I take care to go to my classes on time. It can be said that I am punctual in this regard.

Sample expressions of the participants under the main theme of teaching methods;

P4: I use pair work a lot, question-answer sometimes problem solving anyway, command method is always used.

P9: I use the show-and-do method a lot because I think that if we want to develop a skill in the field of physical education, it is absolutely necessary to present it visually to the student. I show and then I use the command method, narration method, question and answer, paired working methods apart from sanction.

P1: I usually apply the command method and the pairing method. One of the methods I use for question and answer and showing and getting it done.

Table 7. Metaphors of the participants about physical education and sports teaching

\begin{tabular}{lll}
\hline Theme & Metaphor & F \\
\hline Physical Characteristics & Forest & 4 \\
& Oasis & 8 \\
& Desert & - \\
Personality Characteristics & Forest & 8 \\
& Oasis & 4 \\
\multirow{5}{*}{ Teacher Leadership Style } & Desert & - \\
& Forest & 7 \\
\multirow{3}{*}{ Teaching Methods } & Oasis & 5 \\
& Desert & - \\
& Forest & 8 \\
& Oasis & 4 \\
\hline
\end{tabular}

In Table 7, the frequencies of the metaphor images that the participants preferred for four main themes among their metaphors about physical education and sports teaching (forest, oasis, desert) were examined. It is seen that the most preferred metaphor in the main theme of physical characteristics is oasis $(n=8)$, the main theme of personality traits is forest $(\mathrm{n}=8)$, the main theme of teacher leadership stylesis forest $(\mathrm{n}=7)$, and the main theme of teaching methods is forest $(\mathrm{n}=8)$. 
Table 8. Opinions of the participants about their ideal physical education teacher and the physical education students they train

\begin{tabular}{|c|c|c|c|}
\hline THEME & SUB- THEME & CODING & $\mathrm{f}$ \\
\hline \multirow[t]{18}{*}{ Ideal physical education teacher } & \multirow[t]{3}{*}{ Physical characteristics } & Athletic-fit & 10 \\
\hline & & Sportswear & 9 \\
\hline & & Clean-maintained & 8 \\
\hline & \multirow[t]{7}{*}{ Personality characteristics } & Constructive-positive & 5 \\
\hline & & Sweet-hard & 4 \\
\hline & & Feel a sense of belonging & 3 \\
\hline & & Punctual & 3 \\
\hline & & Effective communication & 3 \\
\hline & & Fair-egalitarian & 2 \\
\hline & & Contemporary & 2 \\
\hline & \multirow{6}{*}{ Teacher leadership style } & Field knowledge is sufficient. & 8 \\
\hline & & Role model & 3 \\
\hline & & High academic achievement & 3 \\
\hline & & Idealist & 3 \\
\hline & & Student-centered & 2 \\
\hline & & Good classroom management & 2 \\
\hline & \multirow[t]{2}{*}{ Teaching Methods } & Must use special teaching methods & 5 \\
\hline & & Teaching methods should be diversified in courses & 4 \\
\hline \multirow[t]{11}{*}{ Trained physical education teacher } & \multirow[t]{5}{*}{ Ideal } & Feeling belonging to their profession & 3 \\
\hline & & Hard-working & 3 \\
\hline & & Appropriate physical appearance & 2 \\
\hline & & Appropriate style of clothing & 2 \\
\hline & & High academic achievement & 2 \\
\hline & \multirow[t]{6}{*}{ Non-Ideal } & Non-standard education & 3 \\
\hline & & Irresponsible students & 3 \\
\hline & & Inappropriate style of dressing & 2 \\
\hline & & Lack of materials and facilities & 2 \\
\hline & & Inappropriate physical appearance & 2 \\
\hline & & Not idealistic & 2 \\
\hline
\end{tabular}

In Table 8, when the views of the participants about the ideal physical education teacher and the physical education students they train are examined; It is seen that there are two main themes (ideal physical education teacher, physical education teacher they train). Under the main theme of the ideal physical education teacher, 4 sub-themes were created: physical characteristics, personality traits, teacher leadership styles and teaching methodsUnder the physical feature sub-theme, those with the highest frequency were athletic-fit $(n=10)$, sportswear $(n=9)$ and clean-groomed $(n=8)$; The codings with the highest frequency under the personality trait sub-theme were constructive-positive $(n=5)$ and sweet-hard $(n=4)$; Under the teacher leadership styles sub-theme, content knowledge is sufficient $(n=8)$ and being a role-model $(n=3)$, academic success is high $(n=3)$, idealistic $(\mathrm{n}=3)$; In the teaching methods sub-theme, it is seen that the coding with the highest frequency should use special teaching methods $(n=5)$ and provide a variety of teaching methods in the lessons $(n=4)$.

Two sub-themes, ideal and non-ideal, were created under the main theme of the physical education teacher they trained. The highest frequency coding under the ideal sub-theme was determined by professional belonging $(\mathrm{n}=3)$ and those who love their job $(n=3)$; It is seen that the codings with the highest frequency under the non-ideal sub-theme are non-standard education $(n=3)$ and irresponsible students $(n=3)$. 


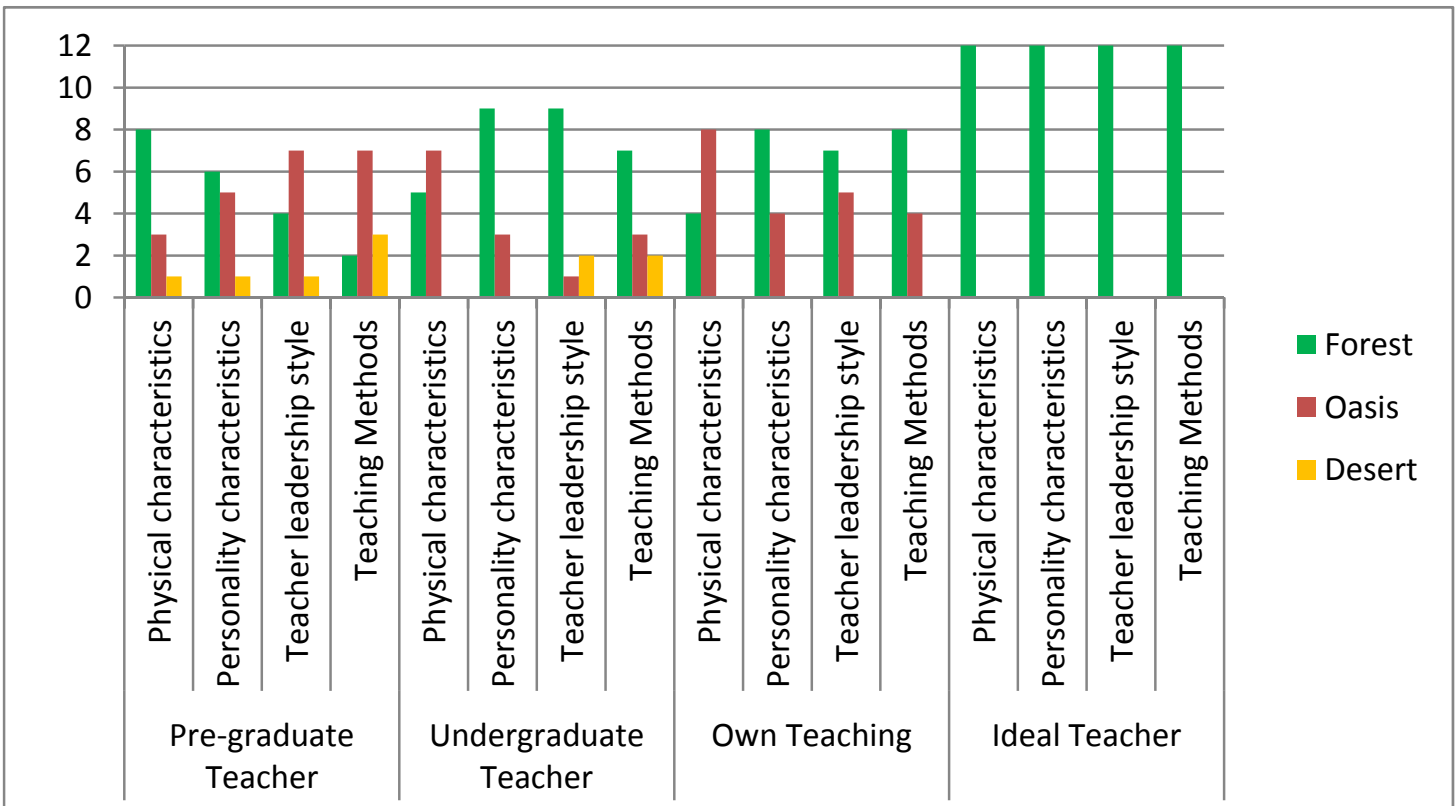

Figure 2. Comparison of participants' metaphorical perceptions of pre-graduate, undergraduate, themselves and their ideal physical education teacher

When the graph is examined, it is seen that the participants metaphorized the ideal physical education teacher as a forest within four main themes. In this sense, when we compare the ideal teacher with the forest metaphor as a metaphorical perception; In the physical feature theme, which is one of the main themes, it is seen that pre-graduate physical education teachers highly prefer the forest metaphor, while they metaphorize the physical education teachers and themselves as oasis. In the main theme of personality traits, type of teacher and teaching methods, it is seen that undergraduate physical education teachers and themselves prefer the forest metaphor with a more intense frequency. It is seen that physical education teachers before undergraduate education prefer the metaphor of oasis more intensely in terms of teaching type and teaching methods. Based on this graph, it can be said that while the participants see the pre-graduate teachers close to the ideal teacher in terms of their physical characteristics, they find the undergraduate physical education teachers and themselves close to the ideal physical education teacher in terms of personality traits, teacher leadership stylesand teaching methods.

\section{Discussion}

In this research, it is aimed to reveal the ideal physical education teacher profile from the perspective of physical education teacher educators, that is, academicians working in the physical education and sports teaching department of the faculty of sports sciences. In this context, as a result of the questions asked to the participants about the physical education teachers who made the most impact on them before and during the undergraduate education, themselves as an academician, their ideal physical education teacher and the physical education teachers they graduated, four main themes (physical characteristics, personality traits, teacher leadership stylesand teaching methods). In this section, each main theme is discussed separately in itself.

\section{Comparison of the opinions of the participants about the physical education teachers who affect them the most in their education life, themselves and the ideal physical education teacher under the theme of physical characteristics}

The opinions of the participants about the physical education teacher who influenced them the most before their undergraduate education are grouped under the sub-themes of height, gender and appearance in terms of physical characteristics. Accordingly, it is seen that the teachers are generally tall, male, clean/well-groomed, athletic/fit and sporty. In addition, teachers are most likened to the 'forest' in terms of metaphors. The opinions of the participants about the physical education teacher who influenced them the most in their undergraduate education are grouped under the sub-themes of height, gender and appearance in terms of physical characteristics. According to this, it is seen that the teachers are generally of medium height, male, clean/well-groomed and sporty. In addition, teachers are mostly likened to oasis in terms of metaphor. It is seen that the participants describe themselves as educators under the sub-themes of height and appearance in terms of physical characteristics. Accordingly, it is seen that the number of participants who define themselves as tall or short is 
equal $(n=5)$. In terms of appearance, the participants describe themselves as clean/well-groomed and athletic/fit. In terms of metaphor, participants often liken themselves to an oasis. It is seen that the participants define their ideal physical education teacher as physically athletic/fit, dressed sportively and clean/well-groomed. In terms of metaphor, the participants expect their ideal physical education teacher to be like a forest.

It is seen that the participants define their ideal physical education teacher as physically athletic/fit, dressed sportively and clean/well-groomed. In terms of metaphor, the participants expect their ideal physical education teacher to be like a forest. In another study, Yoncalık (2002) concluded that in the eyes of athlete students, the ideal physical education teacher should be healthy in terms of body and soul. Similarly, Mizrak Karc1 (2016) emphasizes that the ideal teacher should be healthy. These results are in line with the findings of the current study on athletic and fitness. Considering all these, it can be said that physical appearance is a criterion that comes to mind when the ideal physical education teacher is mentioned and the ideal physical education teacher should be athletic/fit, clean/attentive. In addition, it is seen that the physical education teachers who make an impact on the participants and the physical education teachers in their ideals have similar characteristics.

Comparison of the opinions of the participants about the physical education teachers who affect them the most in their education life, themselves and the ideal physical education teacher under the theme of personal characteristics

The opinions of the participants about the physical education teacher who influenced them the most before their undergraduate education are grouped under the sub-themes of compatibility, extroversion and responsibility in terms of personality characteristics. According to this, it is seen that teachers are paternalistic, sweet-hard, idealistic, self-sacrificing, fair/reliable and disciplined. Teachers are most likened to the forest in terms of personality characteristics. The opinions of the participants about the physical education teacher who influenced them the most in their undergraduate education are grouped under the sub-themes of adaptability, neuroticism and responsibility in terms of personality characteristics. According to this, it is seen that there are teachers who are not communicative as well as teachers who are open to communication, that there are teachers who have a fatherly-motherly attitude as well as those who have a harsh attitude, and that they have a disciplined and fair/reliable structure. When examined in terms of metaphor, teachers are mostly likened to the forest. When the participants defined themselves as an educator in terms of personality characteristics, it was seen that three sub-themes emerged as agreeableness, extraversion and neuroticism. Accordingly, most of the participants describe themselves as soft-hearted, sharing, sweet-hard, kind, fatherly-motherly, open to communication and empathetic. In addition, it is seen that there are participants who express themselves as closed to communication and harsh. In terms of metaphor, participants often liken themselves to a forest. It is seen that the participants expect their ideal physical education teacher to be constructive-positive and sweet-hard as a personality characteristic.

As a metaphor, the participants think their ideal physical education teacher as a forest in terms of personality characteristics. In the literature, Altunbay and Alaca (2021), who discuss the subject from a different perspective, found that the ideal teacher model was defined by watching teacher-themed films. It is seen that there are qualities such as high communication skills. These results are similar to the personality characteristics of the ideal teacher in the current study. In addition, in the current study, it is seen that the participants mainly emphasized the positive aspects of the personality traits of their teachers in the past, and when the undergraduate period and afterward are examined, it is seen that the negative characteristics of the teachers, such as being closed to communication and being harsh, are also highlighted. This situation can be explained by the changes in the profession and student profiles from past to present. Coşkun Keskin and Yüceer (2017) revealed that teachers think that their profession has become unimportant from past to present due to internal and external reasons. This changing position of the teaching profession may have caused teachers to exhibit a more rigid and closed attitude over time. Apart from the current situation, when the ideal teacher perceptions are examined, it is seen that the participants want the teachers to have a constructive attitude regardless of these negativities. This situation shows us that the current situation and the desired situation do not coincide. The difficulties encountered in real life may have pushed people to draw a line outside of the ideal.

\section{Comparison of the opinions of the participants about the physical education teachers who affect them the most in their education life, themselves and the ideal physical education teacher under the theme of teacher type}

When the opinions of the participants about the physical education teacher who influenced them the most before their undergraduate education were examined under the main theme of teacher type, it was seen that they were grouped under the sub-themes of democratic/tolerant, theocratic/authoritarian and free/indifferent. According to this, it is seen that the teachers are not only just/egalitarian and caring for the student, but also disciplined, 
oppressive, non-teaching and indifferent to students. With all these aspects, it is often compared to the metaphor of an oasis in the eyes of the teachers. When the views of the participants about the physical education teacher who influenced them the most in their undergraduate education are examined under the main theme of teacher type, it is seen that they are grouped under the sub-themes of democratic/tolerant, theocratic/authoritarian and classroom teacher. Teachers are fair/egalitarian, open to communication, punctual, disciplined, and have high field knowledge. In terms of metaphor, teachers are most likened to the forest. When the participants defined themselves as educators in terms of teacher type, sub-themes of democratic/tolerant, theocratic/authoritarian and slowed down teacher emerged. Accordingly, the participants are of the role model, fair/egalitarian, caring, punctual and disciplined type, but there are also those who describe themselves as having insufficient classroom control and low motivation. Along with all these features, the participants mostly liken themselves to the forest metaphor.

Looking from the past to the present, the fact that the physical education teachers, who made the most impact on the participants, exhibited a fair and caring attitude to the students, is among the most frequently emphasized by the participants. In addition, the participants stated that their undergraduate teachers have high content knowledge and they expect their ideal teacher to have high content knowledge. Looking at the literature on the subject, Demirhan, Coşkun and Altay (2002) found that in their study to determine the opinions of physical education teachers from the eyes of students, pre-service teachers, teachers and instructors, the most important qualities are understanding students in every subject and having a high level of human relations. It is seen that there are features of being competent in professional knowledge and skills. It can be said that the mentioned qualifications show parallelism with the characteristics in the teacher leadership styles theme in the current study. On the other hand, Sarier (2020) states that the ideal teacher should have a just, supportive, reliable, role model, and effective communicator style in his research that reveals the ideal teacher characteristics from the eyes of vocational high school students. Considering the study, which includes the findings supporting the results of the current study, it can be said that the qualifications expected from teachers, regardless of branch, meet at common points.

Participants think that their ideal physical education teacher should have sufficient field knowledge, a role-model, high academic success, and draw an idealistic profile. Again, in terms of metaphor, it is expected that the ideal physical education teacher will be like a forest.

\section{Comparison of the opinions of the participants about the physical education teachers who affect them the most in their education life, themselves and the ideal physical education teacher under the theme of teaching methods}

When the views of the participants about the physical education teacher who most influenced them before their undergraduate education were examined in terms of the teaching methods they used, it was seen that the sub-themes of general teaching methods and special teaching methods emerged, showing and telling method from general teaching methods, command method and co-working methods from special teaching methods appears to be used. It is seen that teachers are likened to an oasis as a metaphor. When the opinions of the participants about the physical education teacher who influenced them the most in their undergraduate education were examined in terms of the teaching methods they used, sub-themes of general teaching methods and special teaching methods emerged. It is seen that the practice method and the paired working method are mainly used. Participants liken their teachers to a forest in terms of metaphor. It is seen that the teaching methods used by the participants as an educator are grouped under two general and specific sub-themes, and they use demonstration, lecture, question-answer methods from general teaching methods, paired study, problem solving, command and directed discovery methods from special teaching methods. With all these features, the participants liken themselves to the forest metaphor in terms of teaching methods. Participants emphasize that their ideal physical education teacher should use special teaching methods in the use of teaching methods and provide a variety of methods in the lessons, and they liken the teachers related to the subject to the forest metaphor.

In the literature, it is seen that there are different studies on the subject (Cuellar-Moreno, 2016; İnce \& Hünük, 2010; Loghmani, Gholidahaneh, \& Hassannejad, 2018; Yıldız \& Kangalgil, 2013). Although it is seen that teachers use both general and special teaching methods together for each term, it is seen that the use of student-centered methods increases as we go from the past to the present and the future. This can be explained by changing student needs and education systems. Today, the adoption of an educational approach that puts the student in the center and directs them to research and discover knowledge may encourage teachers to use student-centered methods.

In terms of metaphors, it can be said that teachers are generally gathered under the metaphors of forest and oasis 
in the main themes of physical characteristics, personal characteristics, teacher leadership stylesand teaching methods. In this study, forest and oasis metaphors represent profiles that are close to ideal. From this point of view, it can be said that when the participants were asked "the physical education teacher who made the most impact", the teachers that came to mind were the ones who left positive impressions on them and that these teachers were mostly close to the ideal. Similarly, their metaphorical definition of themselves as oasis and forest can be interpreted as they see themselves as suitable for the ideal teacher profile.

Finally, when the participants look at the physical education teachers they have trained with their ideal teacher profile, they are of the opinion that the teachers they train meet their ideal profile in terms of professional belonging, doing their job with pleasure, but there are also teachers who move away from the ideal because the education is not standardized and the students are irresponsible. Considering that today's students are students in the $\mathrm{Z}$ generation, the fact that they are more in technology and less inclined to take responsibility compared to previous generations supports this idea of the participants (Karadoğan, 2019).

\section{Conclusion and Recommendations}

In this study, the views of academicians working in institutions that train physical education teachers on the ideal physical education teacher profile are presented under the main themes of physical, personal, teacher leadership styles and teaching methods. As a result, it can be said that the academicians who are responsible for training physical education teachers in universities, which have an important place in educational activities, reflect the teachers who left their mark on them in the past, themselves as an educator, the teacher profiles they trained and their ideals are close to the ideal at a similar level, and they reflect the reflections of the teachers they are impressed on themselves and on the students they train.

Based on this result, considering that academicians working in universities, which have an important place in education, can leave a mark on the students they train, it is recommended that academicians try to reach ideal levels by constantly improving themselves in terms of physical, personal and educational activities.

\section{Resources}

Ağaoğlu, E. (2007). General Facts about Classroom Management. In Z. Kaya (Ed.), Classroom Management. Ankara: Pagem A Publishing

Altunbay, M., \& Alaca, J. (2021). The 'ideal teacher' model presented in teacher-themed movies. Journal of National Education, 50(230), 409-422. https://doi.org/10.37669/milliegitim.685711

Bilici, M. (2005). Investigation of expectations and evaluations of school administrators from ideal physical education teachers (Sakarya province example). Master's thesis. Retrieved from https://acikerisim.sakarya.edu.tr/handle/20.500.12619/92720

Bird, E. (2003). Quantitative and qualitative research techniques. Ankara: Memoir Publishing.

++-Büyükkaragöz, S. S., \& Çivi, C. (1997). Genel Öğretim Metodları. Konya: Öz Eğitim Basım Yayın Dağıtım Ltd. Şti.

Coşkun Keskin, S., \& Yüceer, D. (2017). Teaching profession as a profession from the perspective of teachers from past to present. Turkish Studies, 12(14), 85-104. https://doi.org/10.7827/TurkishStudies.11694

Cullear-Moreno, M. (2016). Effects of the command and mixed styles on student learning in primary education. Journal of Physical Education and Sport, 16(4), 1159-1168. Retrieved from https://efsupit.ro/images/stories/nr4.2016/art186.pdf

Demirbolat, A. (2006). Classroom Environment and Group Interaction. In L. Kucukahmet (Ed.), Classroom Management. Ankara: Nobel Publication Distribution.

Demirel, O. (2004). Didactics. Ankara: Pegem A publishing.

Demirhan, G. (2006). Fundamentals of Sports Education. Ankara: Spor Publishing House and Bookstore Bağırgan Publishing.

Demirhan, G., Coşkun, H., \& Altay, F. (2002). Opinions on the qualifications of physical education teachers. Education and Science, 27(123), 35-41. Retrieved from http://eb.ted.org.tr/index.php/EB/article/view/5171/1300

Erdogan, I. (2001). Classroom Management. Istanbul: Sistem Publishing.

Güllü, M., \& Arslan, C. (2009). Leadership styles of physical education teachers. Journal of Mustafa Kemal University Institute of Social Sciences, 6(11), 352-367. 
Ince, M. L., \& Hunuk, D. (2010). The teaching styles and perceptions of experienced physical education teachers in the education reform process. Education and Science, 35(157), 128-139.

Isler, H. (2012). Physical Education and Sports Information Guidebook. Istanbul: Ol Book.

Karadogan, A. (2019). Generation Z and the teaching profession. A $\breve{g r}$ İbrahim Çeçen University Journal of Social Sciences Institute, 5(2), 9-41.

Loghmani, M., Gholidahaneh, M., \& Hassannejad, M. (2018). The effect of physical educator's teaching styles on student's goal orientation. Research on Educational Sport, 6(15), 53-72. https://doi.org/10.22089/res.2017.4426.1325

Macnaughton, G., \& Williams, G. (1998). Techniques for Teaching Young Children in Theory and Practice. Australia: Addison Wesley Longman Australia

MEB. (1997). Physical education teacher training program of higher education institutions that train teachers. Ankara: Ministry of National Education.

Mizrak Karc1, M. (2016). Characteristics of the ideal teacher from the student's point of view: The example of Gazi vocational and technical Anatolian high school. Journal of National Education, 209, 80-101.

Mosston, M., \& Asworth, S. (2001). Physical Education Teaching (Translation: Eda Tüzemen). Ankara: Bagirgan Publishing.

Sarier, Y. (2020). Ideal teacher characteristics and skills through the eyes of vocational high school students. Journal of Anadolu University Faculty of Education, 4(4), 294-306. https://doi.org/10.34056/aujef.711581

Seçgel, N. (2005). Leadership styles of music teachers. Unpublished Master's Thesis. Istanbul: Marmara University, Institute of Educational Sciences.

Tamer, K., \& Pulur, A. (2001). Special teaching methods in physical education and sports. Ankara: Kozan Offset.

Tertemiz, N. (2006). Classroom Management and Discipline. In L. Kucukahmet (Ed.), Classroom Management. Ankara: Nobel Publication Distribution.

Ünlü, H., \& Aydos, L. (2007). Teaching methods used by physical education teachers working in primary schools. Niğde University Journal of Physical Education and Sport Sciences, 1(1), 40-50.

Yıldırım, A., \& Şimşek, H. (2018). Qualitative research methods (11th ed.). Ankara: Seçkin Publishing.

Yıldı, E., \& Kangalgil, M. (2013). Examining the opinions of physical education teachers about their professional competencies and the teaching methods they use. Pamukkale Journal of Sports Sciences, 5(1), $61-76$.

Yoncalık, O. (2002). The way of perceiving the ideal teacher profile of the athlete students studying in secondary education (Kurkkale province example). Master's thesis. Retrieved from http://acikerisim.kku.edu.tr/xmlui/bitstream/handle/20.500.12587/16030/115340.pdf?sequence=1\&isAllow ed $=\mathrm{y}$

\section{Copyrights}

Copyright for this article is retained by the author, with first publication rights granted to the journal.

This is an open-access article distributed under the terms and conditions of the Creative Commons Attribution license (http://creativecommons.org/licenses/by/4.0/). 